\title{
Sensitivity of RegCM3 Simulated Precipitation over Southern Brazil with Different Boundary Conditions: ENSO Case
}

\author{
Simone Erotildes Teleginski Ferraz ${ }^{1,2}$ and Diego Pedroso ${ }^{2}$ \\ ${ }^{1}$ Department of Physics, Federal University of Santa Maria, Roraima Avenue 1000, 97105-360 Santa Maria, RS, Brazil \\ ${ }^{2}$ Meteorology Graduate Program, Federal University of Santa Maria, Roraima Avenue 1000, 97105-360 Santa Maria, RS, Brazil \\ Correspondence should be addressed to Simone Erotildes Teleginski Ferraz; simonetfe@ufsm.br
}

Received 9 April 2013; Revised 13 June 2013; Accepted 4 July 2013

Academic Editor: Sergio H. Franchito

Copyright ( 2013 S. E. Teleginski Ferraz and D. Pedroso. This is an open access article distributed under the Creative Commons Attribution License, which permits unrestricted use, distribution, and reproduction in any medium, provided the original work is properly cited.

\begin{abstract}
This paper investigates the capability of a regional climate model (RegCM3) to simulate the Southern Brazil rainfall during three periods: the El Niño (1982), the neutral intermediary phase (1985), and the La Niña (1988). Each integration has used three of different boundary conditions available: NCEP-NCAR Reanalysis (I and II) and ECMWF Reanalysis-ERA-40. The simulations were performed covering a South America domain and some descriptive statistics analyses have been applied, like arithmetic mean, median, standard deviation and Pearson's correlation; and frequencies histogram over Southern Brazil. The main results show that the model satisfactorily reproduces the rainfall in this region during the El Niño, neutral, and La Niña events, indicating that the boundary conditions which were tested adequately describe this simulations type.
\end{abstract}

\section{Introduction}

In Southern Brazil, the Rio Grande do Sul (RS) state has uniform precipitation during the year, with accumulated values around $1800 \mathrm{~mm} /$ year [1]. The climate in this region is affected by many meteorological phenomena, for example, cold fronts [2,3], mesoscale convective systems [4], or El Niño phenomenon $[5,6]$.

The regional climate model-version 3 (RegCM3) model (see more details in [7]) - has been used to solve highresolution local circulation by dynamic downscaling. The information is consistent with the large-scale circulation supplied by the driving GCMs or by reanalysis data at the boundaries [8].

Regional climate models (RCMs) have been used for a wide variety of studies of the present-day climate and possible future climates over a number of regions throughout the world. In the CLARIS-LPB project, the capability of a set of 7 coordinated regional climate models in reproducing the mean climate conditions over the South American continent was evaluated. Results show that the RCMs ensemble adequately reproduces these features, with biases mostly within $\pm 2^{\circ} \mathrm{C}$ and $\pm 20 \%$ for temperature and precipitation, respectively. However, some systematic biases were detected over the La Plata Basin region, such as underestimation of rainfall during winter months and overestimation of temperature during summer months [9]. The dry bias during winter in the Southeast of South America has also been observed in [10].

A RegCM3 was able to simulate the dramatically different large-scale circulations during La Niña and El Niño events in Amazon basin. The regional model showed reduction of rainfall in the western Amazon when compared to the observed estimates. This precipitation is associated to weak low-level moisture transport from the Atlantic [11]. The capabilities of two regional models (RegCM3 and the climate version of the CPTEC Eta model) were evaluated to simulate the summer quasi-stationary circulations over South America during El Niño and 1998-1999 La Niña. In general, the results showed that both models are capable of capturing the main changes of the summer climate over South America during these two extreme cases and, consequently, they have potential to predict climate anomalies [12].

In the Southeast of South America, for example, winter is the dry season; however, this feature is not observed in 
Southern South America (studied here). So, this is a recurrent problem in climate forecasts in Southern Brazil; rainfall is much less frequent than the observed values during the winter season $[9,10]$. In middle latitudes, types of phenomena that generate precipitation in the winter are varied and many of these phenomena are not adequately reproduced by both global and regional models [13].

Therefore, the main goal of this research is to assess the ability of the RegCM3 model in simulating the behavior of regional precipitation in the RS state using three different boundary conditions. The results were compared to current data. The analysis was performed for neutral year, El Niño year, and La Niña year. The choice of simulating ENSO events (El Niño and La Niña) is due to the fact that this event is well known and researched by several scientists. Its implications were described to all regions of the planet, as seen in [5].

\section{Materials and Methods}

The model was initially developed at the National Center for Atmospheric Research (NCAR) from the Mesoscale Model version 4 (MM4) [14]. The model solves primitive equations for a compressible atmosphere, using finite differences and vertical sigma pressure coordinate. The parameterization of convective precipitation still remains one of the most important sources of errors in climate models. Three options are available in RegCM3 to represent cumulus convection: (a) modified-Kuo scheme [15], (b) Grell scheme [16], and (c) MIT-Emanuel scheme $[17,18]$. Was this research Grell scheme with Arakawa-Schubert closure was adopted [19]?

Initial model and lateral boundary conditions were created with NCEP-NCAR Reanalysis I (hereinafter NNRP1) [20], NCEP-NCAR Reanalysis II (hereinafter NNRP2) [21], and, finally, the Reanalysis of the European Centre for Medium Range and Weather Forecasts (hereinafter ERA40) [22]. SSTs were obtained from HadISST 1.1 [23]. HadISST1 improves upon previous global sea ice and SST (GISST) data sets: GISST1 [24], GISST2 [25], and GISST3, all developed at the Met Office Hadley Centre. HadISST1 is globally complete, gaps in the SST data have been interpolated, and sea ice concentrations have been supplied in the ice zones. Land cover and topography are specified using the Global Land Cover Characterization (GLCC) version 2 data provided by the U.S. Geological Survey (USGS) Earth Resources Observation System Data Center [26], respectively, with horizontal resolution of $10 \mathrm{~min}$ being used to provide the terrain characteristics.

The regional model is integrated over the domain of Figure 1 for the years 1982, El Niño event (hereafter Nino82, integrated from 00:00 UTC of December 1, 1981, to 00:00 UTC of February 1, 1983); 1988, La Niña event (hereafter Nina88, integrated from 00:00 UTC of December 1, 1987 to 00:00 UTC of February 1, 1989), and 1985 ENSO-neutral event (hereafter Neutral85, integrated from 00:00 UTC of December 1, 1984, to 00:00 UTC of February 1, 1986), at a spatial resolution of $50 \mathrm{~km}$. The period of simulation extends from December before the year of the events and ends

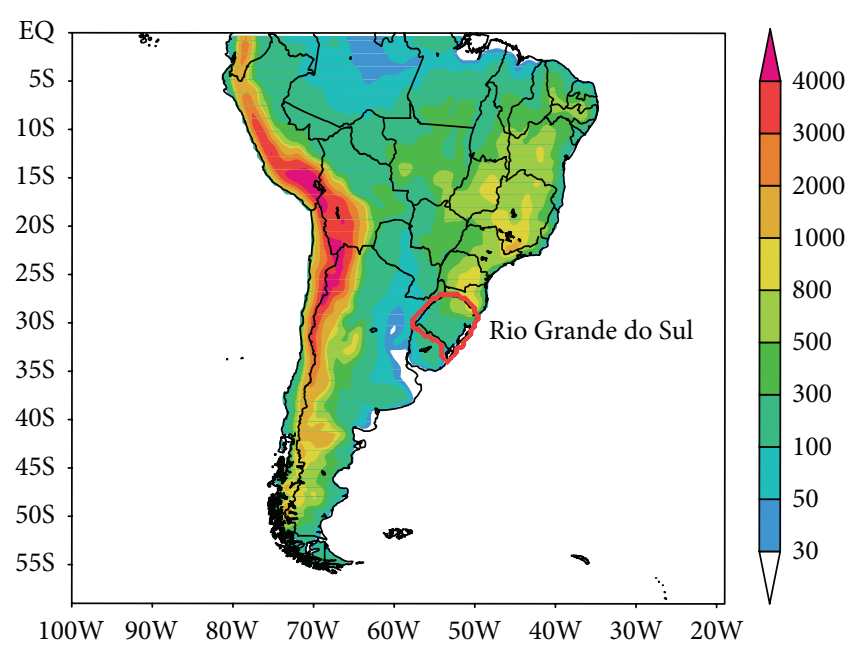

FIGURE 1: The topography model domains and the Rio Grande do Sul state highlighted (height contours are expressed in meters).

in January after the year of the events, but we have only considered the full year (January to December).

The nested modeling technique has been increasingly applied to climate studies in the last few years. Two main theoretical limitations of this technique are the effects of systematic errors in the driving fields provided by global models and lack of two-way interactions between regional and global climate [27-29]. To minimize these problems, the simulated region is considerably large. This area covers from the equator $\left(0^{\circ}\right.$ latitude) to southern Argentina (latitude $60^{\circ} \mathrm{S}$ ). The longitudinal domain extends from the central region of South Pacific Ocean $\left(120^{\circ} \mathrm{W}\right)$ to the central South Atlantic Ocean $\left(20^{\circ} \mathrm{W}\right)$ (Figure 1$)$.

The simulated seasonal precipitation was compared to the South American daily rainfall values (hereafter referred to as REAL) obtained from different sources of observations from the Liebmann and Allured publication [30]. This group of data consists of several daily rainfall sources in South America. The data are combined in fields of grid available in $1^{\circ}$ (used here) and $2.5^{\circ}$ of latitude constructed based on the 7900 stations for the period 1940 to 2012.

The analysis of the model output only uses points in the state of Rio Grande do Sul, in this points was calculated weighted averages of these points. The weight average is the average determined for limits and intervals using the scaling of the default file. The coordinates are converted to the nearest integer grid coordinates based on the scaling of the default file. The average is then performed over the range of these grid coordinates. The average is weighted for nonlinear grid intervals. Averages over latitude are weighted by the delta of the sine of the latitudes at the edge of the grid box. The edges of the grid box are always defined as being the midpoint between adjacent grid points [31].

Thus we have a unique average value $(\mathrm{mm} /$ day) for each day of year, rainy or not, for each boundary condition employed (Figure 1). After that, we performed a descriptive statistical analysis of precipitation series, like mean, median, and standard deviation (Table 1); frequency distribution; and 


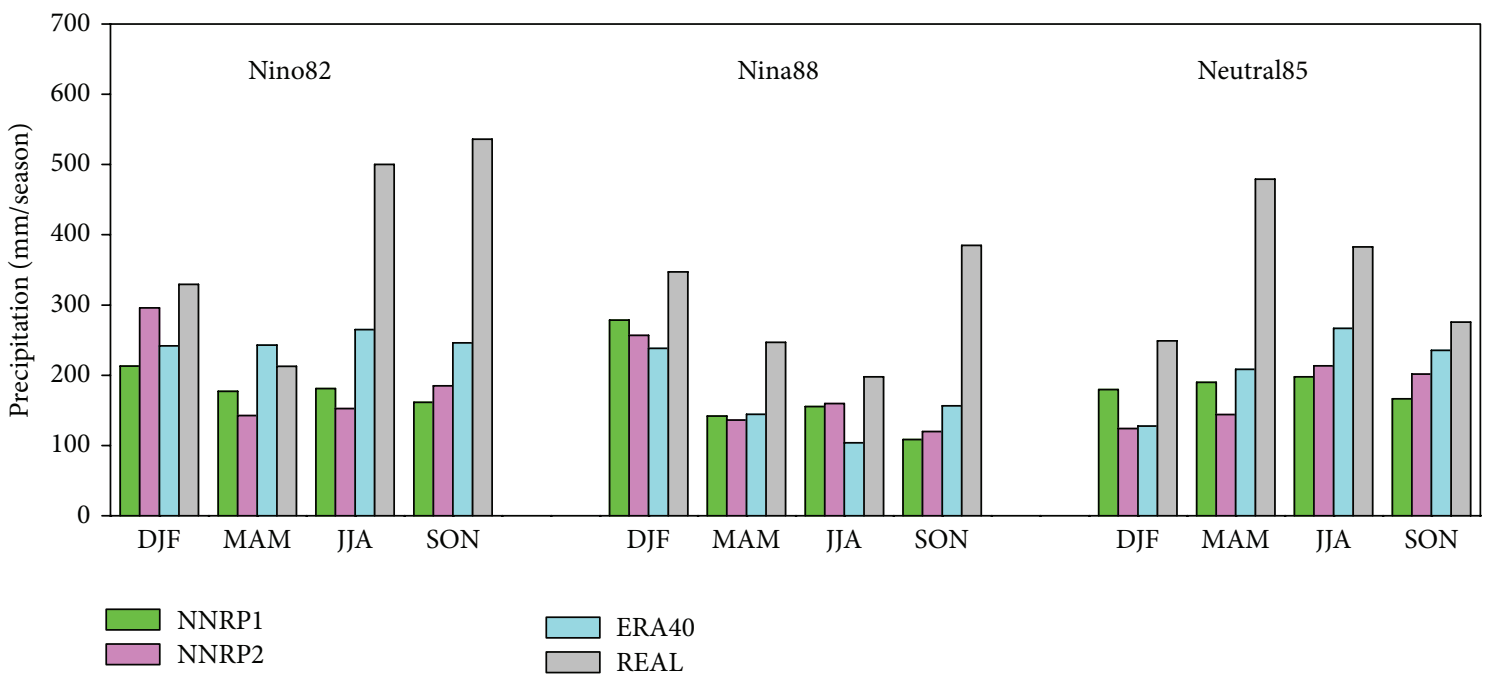

FIgURE 2: Seasonal precipitation for three simulations (colored) and REAL data (gray).

TABLE 1: Summary statistics to three simulations and REAL data for annual values.

\begin{tabular}{lcccc}
\hline Statistics & NNRP1 & NNRP2 & ERA40 & REAL \\
\hline NINO82 & & & & \\
$\quad$ Mean & 2,01 & 2,13 & 2,73 & 4,32 \\
$\quad$ Median & 3,24 & 2,99 & 4,19 & 6,35 \\
$\quad$ Standard deviation & 0,70 & 0,70 & 1,20 & 1,80 \\
NEUTRAL85 & & & & \\
$\quad$ Mean & 2,01 & 1,87 & 2,30 & 3,80 \\
$\quad$ Median & 2,97 & 2,75 & 3,45 & 5,53 \\
$\quad$ Standard deviation & 0,70 & 0,70 & 0,90 & 1,40 \\
NINA88 & & & & \\
$\quad$ Mean & 1,87 & 1,84 & 1,76 & 3,22 \\
$\quad$ Median & 3,08 & 2,65 & 3,00 & 5,16 \\
$\quad$ Standard deviation & 0,50 & 0,60 & 0,40 & 0,80 \\
\hline
\end{tabular}

Pearson correlation coefficient, considering as true the REAL analysis. The Pearson correlation is calculated using the relation above [32]:

$$
r=\frac{\sum_{i=1}^{n}\left(x_{i}-\bar{x}\right) \cdot\left(y_{i}-\bar{y}\right)}{\sqrt{\sum_{i=1}^{n}\left(x_{i}-\bar{x}\right)^{2} \sum_{i=1}^{n}\left(y_{i}-\bar{y}\right)^{2}}}
$$

where $r=$ Pearson correlation coefficient; $x_{i}=$ modeled series; and $y_{i}=$ REAL series; $n=$ series size.

\section{Results}

The three rainfall simulations were generated and their average precipitation was compared with REAL analysis. As expected, positive and negative anomalies of precipitation were observed in south in El Niño and La Niña events, respectively, according [6] in her Figures 9, 10, and 11. The model, in any event, provides less rainfall than REAL analysis (Figure 2). It can be observed that all events are
TABLE 2: Pearson product-moment correlation coefficient between three simulations and REAL data for annual values.

\begin{tabular}{lccc}
\hline Case & NNRP1 & NNRP2 & ERA40 \\
\hline NINO82 & 0,41 & 0,30 & 0,40 \\
NEUTRAL85 & 0,32 & 0,24 & 0,32 \\
NINA88 & 0,46 & 0,40 & 0,49 \\
\hline
\end{tabular}

underestimated, as seen in the figures showing the seasonal rainfall observed (gray bar) and simulated (colored bar).

It is interesting to note that the dry event simulations (NINA88) approach the REAL value, as can be seen in Figure 2. However, only in the SON season we can see that the model cannot represent the rainfall as well as other seasons. For the NINO82 event of the summer months (DJF) and autumn (MAM) and in NEUTRAL85, spring (SON), and summer (DJF), seasons are adequately simulated.

The underestimation of precipitation can also be seen in the statistical analysis in Table 1 . Descriptive variables as mean, median, and standard deviation show that the boundary conditions used agree with each other on estimated precipitation [32]. The average of the REAL data is always greater than the average of the simulations. The interpretation of the values obtained for the mean, median, and standard deviation leads us to infer that the model does not correctly capture extreme values.

For the three simulations, we calculated the Pearson product-moment correlation coefficient for the simulated rainfall and REAL data. For two events, both El Niño and La Niña, the NNRP1 presents the highest correlation value, followed by ERA40, and finally, the series showed that lower correlation was provided by Reanalysis II NCEP (NNRP2). The correlation coefficient agrees with that observed in seasonal values; the La Niña event showed the best results when compared to REAL (Table 2).

To determine the range of precipitation data, a histogram of frequencies was prepared in which relative frequencies 


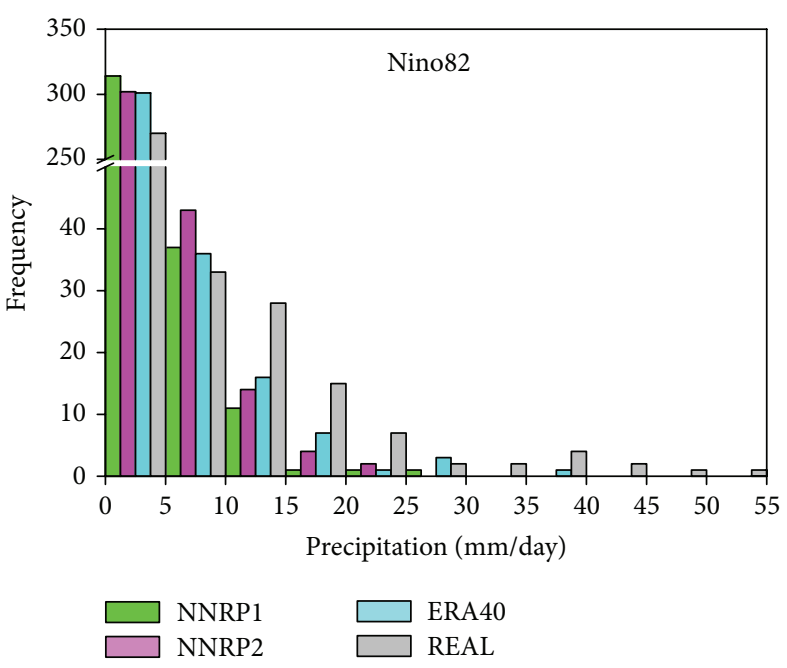

(a)

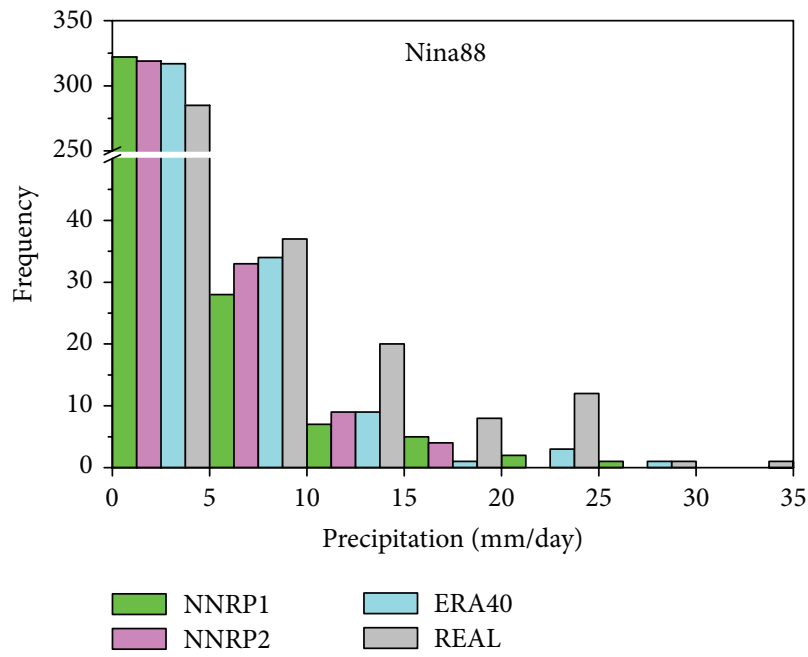

(b)

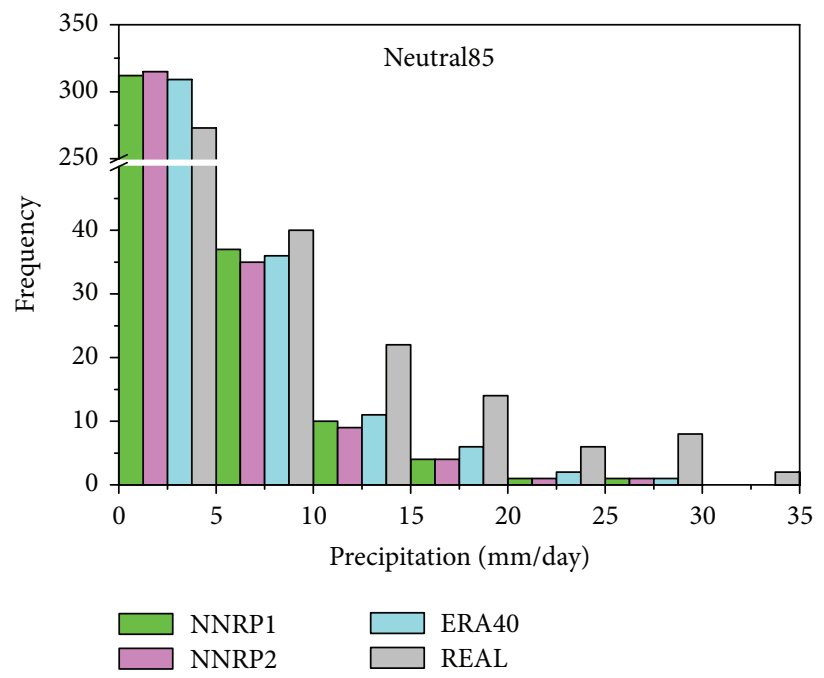

(c)

Figure 3: Frequency histogram to Nino82, Nina88, and Neutral85.

are represented by frequency intervals. This analysis may indicate in which precipitation category the model shows more accuracy; in other words, it checks the skill of RegCM3 in simulating daily accumulated rainfall. Figure 3 shows the graphs to NINO82, NINA88, and NEUTRAL85, respectively. Frequency distribution can confirm the assumptions imposed by descriptive statistics for mean, median and standard deviation mentioned above.

The precipitation events which are found in classes 1 and 2 (having values between 0 and $5 \mathrm{~mm} /$ day and between 5.1 and $10 \mathrm{~mm} /$ day, resp.) are simulated correctly in most cases. This indicates that although the model cannot accurately capture the magnitude of the events, it has the ability to indicate the main patterns of occurrence of precipitation (Figure 3).

Many series in the three simulations are distributed practically until the fourth class, with values between 15.1 and $20 \mathrm{~mm} /$ day. For Nino82, however, it is possible to check that the values in the observed series reach $55 \mathrm{~mm}$ /day in a single event. In El Niño years, it is expected to have accumulated more significant rainfall in southern South America, but there are no simulated values in these classes, confirming the low ability of the model in simulating extreme values (Figure 3).

\section{Summary and Conclusions}

The main objective of this research was to verify the ability of the RegCM3 model to simulate precipitation regimes over the South of Brazil and their respective behavior. The runs are designed for three distinct periods with different boundary conditions during the El Niño phenomenon (wet condition), La Niña (dry condition), and neutral intermediate period (normal condition). Finally, this could indicate the boundary condition to be recommended that best represents the rainfall in Rio Grande do Sul. 
In general, the model shows a tendency to underestimate rainfall amounts over the region, as noted by $[9,10]$.

In wet conditions, high values of accumulated precipitation in southern South America are expected [5, 6]. However, in most cases, the simulations only capture rain events from weak to moderate intensity, on which accumulation is relatively low. This can be evidenced by the frequency histogram distribution, on which it can be observed that precipitation between 0 and $10 \mathrm{~mm} /$ day is satisfactorily simulated and its occurrences are described correctly. On the other hand, events which have intensity between 10 and $25 \mathrm{~mm}$ /day are underestimated. Besides that, values that accumulated over $50 \mathrm{~mm} /$ day were not captured by the model. In normal conditions, the same behavior is observed, but high values are not observed, increasing the accuracy of the model, especially in frequencies between 0 and $10 \mathrm{~mm} /$ day, whose period showed the lower correlation. For the period of dry condition, in which lower accumulated rainfall is expected, the model also simulated lower values.

The Pearson correlation coefficients were higher during El Niño and La Niña years than in the neutral period. This shows that time evolution of daily rainfall is better simulated in ENSO conditions.

As suggested by [33] the horizontal grid model may be one potential reason to explain the differences between model results and observations. The horizontal grid model spacing $(50 \mathrm{~km})$ is too coarse to accurately simulate the synoptic or mesoscale systems over Southern America. Moreover, the physics options used in the integration model are also sources of concern and could lead to differences, particularly the convection scheme. The Grell scheme parameterization was tested by [34] in central South America and also shows that there is a systematic underestimation of precipitation.

However, there is no expectation of an exact concordance between model and observations, and we conclude that this simulation has produced good results in different climate situations. Therefore, the work suggests that there is a potential for using the RegCM model for the study of climate variability over South America.

\section{Acknowledgments}

This work was supported in part by the National Counsel of Technological and Scientific Development CNPq (Projects: 471028/2009-6 and 303851/2009-0) and the Foundation for Research Support of the State of Rio Grande do Sul FAPERGS (PRONEM project). The authors are grateful to two anonymous reviewers for suggestions that improved the paper.

\section{References}

[1] A. M. Ramos, L. A. Rodrigues, and L. T. G. Fortes, Normais Climatológicas Do Brasil 1961-1990, Instituto Nacional de Meteorologia, Brasília, Brazil.

[2] J. J. Taljaard, "Topics: synoptic meteorology in Southern Hemisphere," Meteorological Monographs, vol. 13, no. 35, pp. 129-213, 1972.
[3] I. F. A. Cavalcanti and V. E. Kousky, "Climatology of South America cold fronts," in Proceedings of the International Conference on Southern Hemisphere Meteorology and Oceanography, Wellington, New Zealand, March 2003.

[4] I. Velasco and J. M. Fritsch, "Mesoscale convective complexes in the Americas," Journal of Geophysical Research, vol. 92, no. 8, pp. 9591-9613, 1987.

[5] C. F. Ropelewski and M. S. Halpert, "Global and regional scale precipitation patterns associated with the El Niño/Southern Oscillation," Monthly Weather Review, vol. 115, pp. 1606-1626, 1987.

[6] A. M. Grimm, S. E. T. Ferraz, and J. Gomes, "Precipitation anomalies in southern Brazil associated with El Nino and La Nina events," Journal of Climate, vol. 11, no. 11, pp. 2863-2880, 1998.

[7] J. S. Pal, F. Giorgi, X. Bi et al., "Regional climate modeling for the developing world: The ICTP RegCM3 and RegCNET," Bulletin of the American Meteorological Society, vol. 88, no. 9, pp. 13951409, 2007.

[8] P. Zanis, C. Douvis, I. Kapsomenakis, I. Kioutsioukis, D. Melas, and J. S. Pal, "A sensitivity study of the regional climate model (RegCM3) to the convective scheme with emphasis in central eastern and southeastern Europe," Theoretical and Applied Climatology, vol. 97, no. 3-4, pp. 327-337, 2009.

[9] S. A. Solman, E. Sanchez, P. Samuelsson et al., "Evaluation of an ensemble of regional climate model simulations over South America driven by the ERA-Interim reanalysis: model performance and uncertainties," Climate Dynamics, 2013.

[10] A. Seth, S. A. Rauscher, S. J. Camargo, J. Qian, and J. S. $\mathrm{Pal}$, "RegCM3 regional climatologies for South America using reanalysis and ECHAM global model driving fields," Climate Dynamics, vol. 28, no. 5, pp. 461-480, 2007.

[11] A. Seth and M. Rojas, "Simulation and sensitivity in nested modeling system for South America, part I: reanalysis boundary forcing," Journal of Climate, vol. 16, pp. 2437-2453, 2003.

[12] J. P. R. Fernandez, S. H. Franchito, and V. B. Rao, "Simulation of the summer circulation over South America by two regional climate models, part II: a comparison between 1997/1998 El Niño and 1998/1999 La Niña events," Theoretical and Applied Climatology, vol. 86, no. 1-4, pp. 261-270, 2006.

[13] A. M. Grimm and M. T. Zilli, "Interannual variability and seasonal evolution of summer monsoon rainfall in South America," Journal of Climate, vol. 22, no. 9, pp. 2257-2275, 2009.

[14] R. A. Anthes, E. Hsie, Y. Kuo et al., "Description of the Penn State/NCAR Mesoscale Model Version 4 (MM4)," NCAR Technical Notes NCAR/TN-282+STR, NCAR, Boulder, Colo, USA, 1987.

[15] R. A. Anthes, "A cumulus parameterization scheme utilizing a one-dimensional cloud model," Monthly Weather Review, vol. 105, pp. 270-286, 1977.

[16] G. A. Grell, "Prognostic evaluation of assumptions used by cumulus parameterizations," Monthly Weather Review, vol. 121, no. 3, pp. 764-787, 1993.

[17] K. A. Emanuel, "A scheme for representing cumulus convection in large-scale models," Journal of the Atmospheric Sciences, vol. 48, no. 21, pp. 2313-2335, 1991.

[18] K. A. Emanuel and M. Živković-Rothman, "Development and evaluation of a convection scheme for use in climate models," Journal of the Atmospheric Sciences, vol. 56, no. 11, pp. 1766-1782, 1999. 
[19] A. Arakawa and W. H. Schubert, "Interaction of a cumulus cloud ensemble with the largescale environment, part I," Journal of the Atmospheric Science, vol. 31, pp. 674-701, 1974.

[20] E. Kalnay, M. Kanamitsu, R. Kistler et al., "The NCEP/NCAR 40-year reanalysis project," Bulletin of the American Meteorological Society, vol. 77, no. 3, pp. 437-471, 1996.

[21] M. Kanamitsu, W. Ebisuzaki, J. Woollen et al., "NCEP-DOE AMIP-II reanalysis (R-2)," Bulletin of the American Meteorological Society, vol. 83, no. 11, pp. 1631-1643, 2002.

[22] S. M. Uppala, P. W. Kallberg, A. J. Simmons et al., "The ERA40 re-analysis," Quarterly Journal of the Royal Meteorological Society, vol. 131, pp. 2961-3012, 2005.

[23] N. A. Rayner, D. E. Parker, E. B. Horton et al., "Global analyses of sea surface temperature, sea ice, and night marine air temperature since the late nineteenth century," Journal of Geophysical Research D, vol. 108, no. 14, pp. 1-29, 2003.

[24] D. E. Parker, M. Jackson, and E. B. Horton, "The Gisst2. 2 sea surface temperature and sea-ice climatology," Climate Research Technical Note Crtn63, Hadley Centre, Meteorological Office, Bracknell, UK, 1995.

[25] N. A. Rayner, N. A. Horton, E. B. Parker et al., "Version 2. 2 of the global sea-ice and sea surface temperature data set, 19031994," Climate Research Technical Note Crtn74, Hadley Centre, Meteorological Office, Bracknell, UK, 1996.

[26] T. R. Loveland, B. C. Reed, J. F. Brown et al., "Development of a global land cover characteristics database and IGBP DISCover from 1-km AVHRR data," International Journal of Remote Sensing, vol. 21, no. 6-7, pp. 1303-1330, 2000.

[27] F. Giorgi and L. O. Mearns, "Approaches to the simulation of regional climate change: a review," Reviews of Geophysics, vol. 29, no. 2, pp. 191-216, 1991.

[28] F. Giorgi and L. O. Mearns, "Introduction to special section: regional climate modeling revisited," Journal Geophysics Research, vol. 104, pp. 6335-6352, 1999.

[29] F. Giorgi, B. Hewitson, H. Christensen et al., "Regional climate information-evaluation and projections," IPCC 3rd Assessment Report-Climate Change chapter 10, IPCC, London, UK, 2001.

[30] B. Liebmann and D. Allured, "Daily precipitation grids for South America," Bulletin of the American Meteorological Society, vol. 86, no. 11, pp. 1567-1570, 2005.

[31] B. Doty, “The grid analysis and display system," Manual, vol. 1. 5. 1. 12., 1995.

[32] D. S. Wilks, Statistical Methods in the Atmospheric Sciences, Academic Press, New York, NY, USA, 1995.

[33] E. A. Afiesimama, J. S. Pal, B. J. Abiodun, W. J. Gutowski Jr., and A. Adedoyin, "Simulation of West African monsoon using the RegCM3, part I: model validation and interannual variability," Theoretical and Applied Climatology, vol. 86, no. 1-4, pp. 23-37, 2006.

[34] D. Martínez-Castro, R. da Rocha, A. Bezanilla-Morlot et al., "Sensitivity studies of the RegCM3 simulation of summer precipitation, temperature and local wind field in the Caribbean Region," Theoretical and Applied Climatology, vol. 86, no. 1-4, pp. 5-22, 2006. 

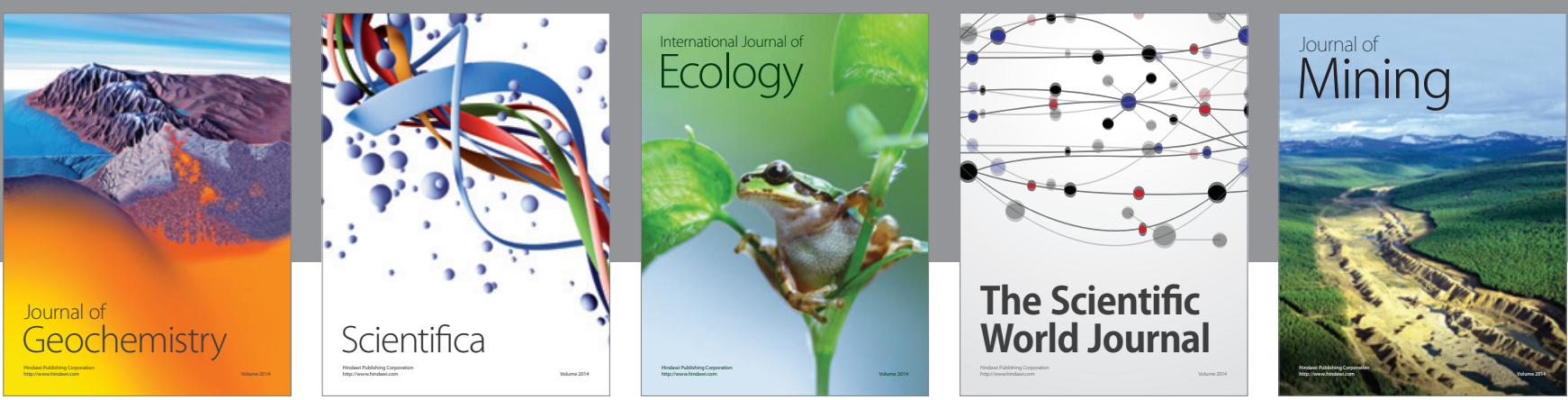

The Scientific World Journal
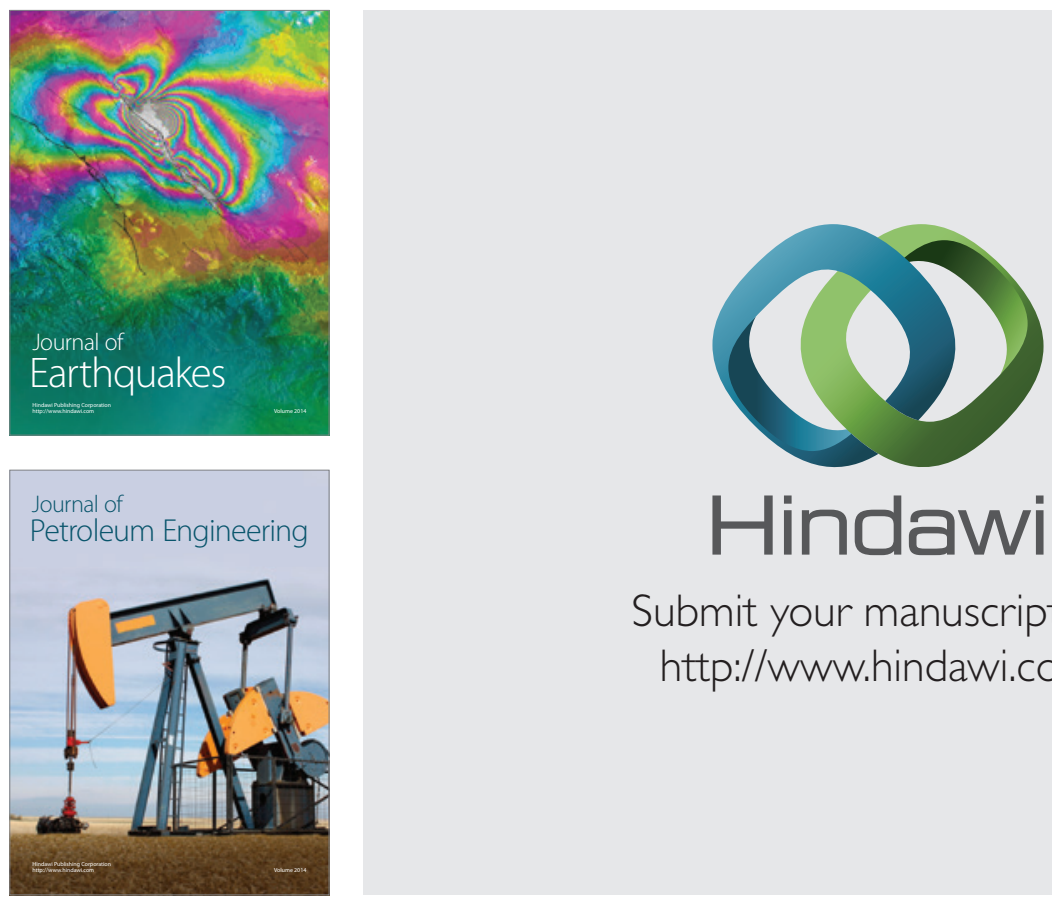

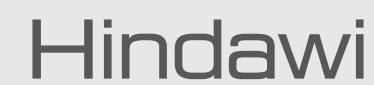

Submit your manuscripts at

http://www.hindawi.com
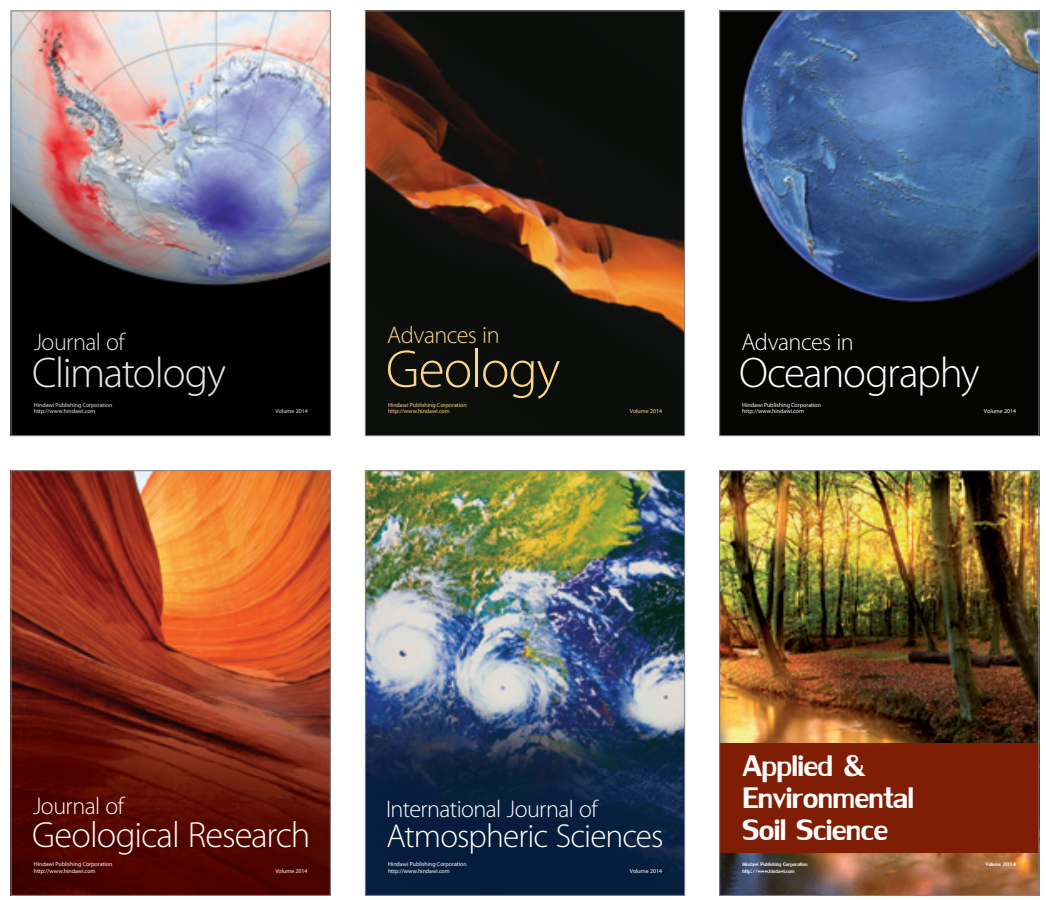
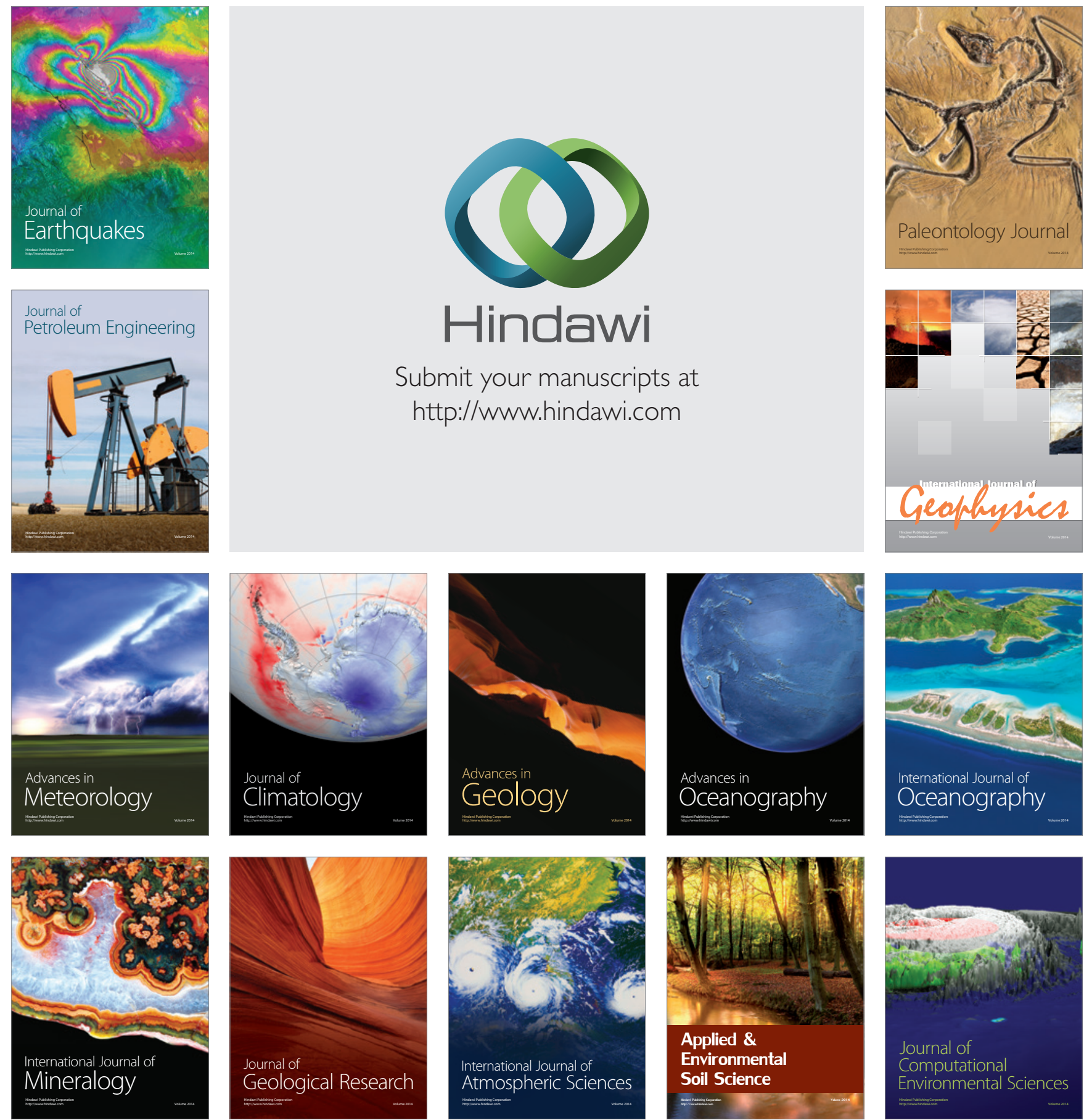